Foi com muita honra e satisfação que aceitamos a incumbência da coordenar esta entrevista, cujo espaço a Dental Press teve a feliz iniciativa de dedicar aos expoentes da Ortodontia. Desta vez o escolhido foi o Prof. Alderico Artese, que responderá às várias perguntas elaboradas por renomadas personalidades da Ortodontia de diferentes regiões de nosso país, com o objetivo de compartilhar experiências clínicas e transmitir informações sobre as mais recentes tecnologias e conceitos, contribuindo para o aprimoramento da Ortodontia brasileira. O entrevistado, paulista de nascimento, tornou-se carioca na adolescência, quando aqui chegou para se preparar para o ingresso na universidade. Em 1962 cursava o terceiro ano do curso de graduação na UFRJ. Na disciplina de Ortodontia, dirigida competentemente pelo saudoso professor José Édimo Soares Martins, já demonstrava um grande interesse pela especialidade, ao lado de uma personalidade forte, com qualidades como dedicação, criatividade e liderança. A brilhante atuação no curso de graduação, aliada ao interesse que manifestou pela Ortodontia, representaram trunfos importantes na conquista pela cobiçada vaga no curso de especialização, com duração de dois anos, em tempo integral, na mesma Universidade, iniciado em 1964. Ao concluir o curso, com êxito, foi convidado a integrar a equipe de docentes da disciplina. Em 1972, o interesse crescente pela Ortodontia o conduziu à Universidade de Washington, onde concluiu novo curso de dois anos, obtendo o grau de mestre. Ao retornar, voltou a acumular a condição de professor e clínico, desempenhando as duas atividades com igual dedicação e proficiência, condição que poucos conseguem. A sua dedicação como professor do curso de pós-graduação em Ortodontia na UFRJ, o mais antigo curso em tempo integral dedicado ao ensino da Ortodontia em nosso país, é reconhecida por todos os seus ex-alunos. A perseverança e o entusiasmo o fizeram portador de um conhecimento amplo e profundo dos diferentes aspectos da especialidade. $O$ aprimoramento constante das técnicas e conceitos aplicados na clínica diária foram importantes na obtenção da excelência dos resultados obtidos. Conferencista nacional e internacional, o Prof. Alderico Artese tem encantado a todos pela qualidade e alto nível dos cursos e conferências ministrados. Por isso, ao longo de sua vida profissional, tem galgado a admiração e o respeito de todos que o conhecem. Para aqueles que não o conhecem, esta entrevista certamente será capaz de comprovar a solidez dos conceitos e sua larga experiência clínica.

Antônio Carlos Peixoto da Silva

\title{
Alderico Artese
}

- Graduado em Odontologia pela Universidade do Brasil em 1963.

- Pós-graduado em Ortodontia pela Universidade Federal do Rio de Janeiro em 1966.

- Master of Sciences in Orthodontics pela University of Washington em 1974.

- Professor Adjunto de Ortodontia da Universidade Federal do Rio de Janeiro de 1966 a 2006.

- Presidente da Sociedade Brasileira de Ortodontia de 1971 a 1972.

- Exerce atividade clínica desde 1966 e proferiu diversas palestras e cursos no Brasil e no exterior.

- Email para contato heliet@uol.com.br

O professor Alderico é filho de Victor Hugo Florial Artese e Maria Gebara de Lima Artese, nascido em 7 de janeiro de 1937 em Vargem Grande do Sul/SP. Casado há 40 anos com Dra. Heliete, também dentista, que o auxiliou durante toda sua vida clínica. Tiveram 4 filhos: Flavia, ortodontista e professora da UERJ; Fernanda, engenheira de produção, trabalhando e vivendo em Londres; Gustavo, advogado, na

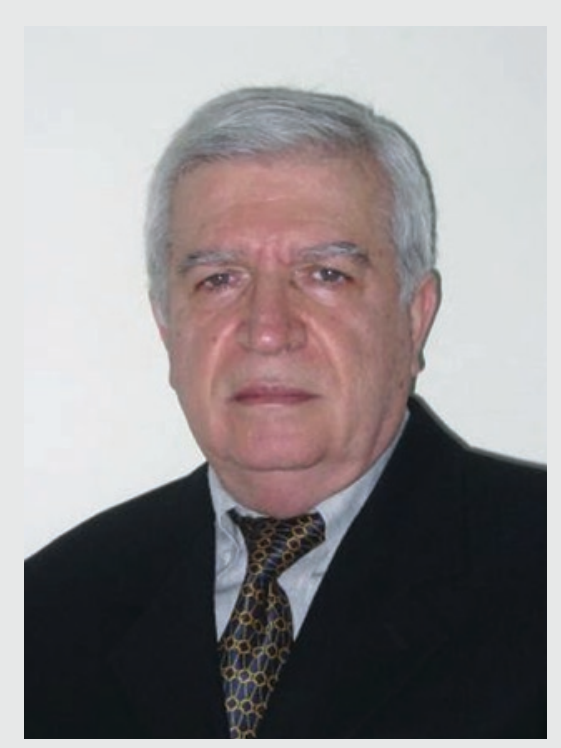
área internacional de telecomunicações, radicado em São Paulo, e Vivian, que é especial e tem um regime de educação e orientação apropriado. Em abril deste ano nasceu sua primeira neta, Ana Julia, filha de Fernanda e seu marido John Baker.

1) Professor Alderico Artese, a sua formação ortodôntica, como especialista, ocorreu na UFRJ, como membro da $4^{\mathrm{a}}$ turma, e depois obteve o título de mestre em Ortodontia na Universidade de Washington, em Seattle-
USA. Ao retornar, passou a fazer parte da equipe coordenada pelo Prof. José Édimo Soares Martins, sendo um dos professores deste grupo. Ao longo dos seus 50 anos de existência, o curso do Fundão formou mais 
de 300 profissionais, muitos reconhecidos no Brasil e no exterior. Como o Sr. se sente partícipe pleno desta obra? Fernando Habib

Sinto orgulho de fazer parte deste grupo e defendo suas posturas com convicção e respeito, percebendo que o esforço e os sacrifícios dispendidos têm sido estimulantes para mais e maior dedicação, e ver, por exemplo, o esmero que foi dado à criação do Curso de Ortodontia da UFBA, que além de ser um centro de excelência é uma das mais representativas homenagens ao professor Martins - patrono da Ortodontia nacional. Porém, percebo que há muito o que se fazer, pois temos que progredir sempre. É interessante analisar o passado e mais interessante ainda é planejar os trabalhos ou ações que venham a beneficiar a todos e à Ortodontia propriamente dita, no futuro. Como você pode verificar, esta obra não será nunca concluída, pois necessitamos progredir sempre e há muito o que se fazer, se é que desejamos permanecer bem colocados no ranking ortodôntico mundial. É dever DE TODOS participar e colaborar, estando sempre presentes e atuantes nas suas sociedades. Ser apenas sócio não significa grande cooperação. Lembrem-se, sempre, que a união faz a força e é necessário estarmos sempre unidos e produtivos. Fico realmente triste quando vejo um colega que não se associa ou, quando associado, não coopera com sua sociedade.

2) Qual a principal diferença do ensino da Ortodontia no Brasil e nos EUA hoje e nos anos $\mathbf{7 0}$ quando o Sr. fez o seu mestrado em Seattle? Marco Antonio de Oliveira Almeida

A principal diferença é o poder aquisitivo, lá eles têm mais dinheiro, compram e pagam tudo nos campos da pesquisa e do ensino. $\mathrm{O}$ americano atual e o do passado são muito parecidos e têm um bom equilíbrio entre ensinamentos clínicos e pesquisa. Eles têm recursos financeiros e são provedores de suas universidades, enquanto em nosso país, nas universidades federais onde trabalhei, o ensino é gratuito. Em passado recente, por orientações no sentido de formarem menor número de ortodontistas americanos, pois o mercado estava saturado, decidiram formar mais estrangeiros e, assim, a aceitação de estrangeiros passou a ser em larga escala nos cursos americanos. Quer por barreira do idioma ou por seleção inadequada dos alunos de pós-graduação, os chamados centros de excelência ficaram prejudicados, não podendo manter o fluxo normal de suas atividades, com isso os alunos americanos foram obrigados a acompanhar a lentidão dos estrangeiros e os prejuízos para o ensino foram enormes. No Brasil as discrepâncias entre ensino e pesquisa continuam acentuadas, mas a principal diferença continua sendo a econômica. Os dois estão em um bom patamar de qualidade, considerando os bons cursos nacionais e americanos (lá existem cursos ruins também), ou de qualquer outro país. Posso dizer, tranqüilamente, que os nossos bons cursos não ficam a dever, se comparados a qualquer bom curso do mundo. Isto é tão verdadeiro para mim que orientei minha filha no sentido de obter formação ortodôntica no Brasil e, posteriormente, buscar no exterior aprimoramento nas atividades de pesquisa, área ainda deficiente no Brasil. Há profissionais em nosso país, como eu mesmo, que foram orientados a cursar um segundo curso no exterior, pois havia ainda muita diferença no ensino para graduados. $\mathrm{Na}$ época foi válido, hoje seria loucura e inaceitável, visto a nossa capacidade de ensino atual.

3) Quais foram, em sua opinião, os principais avanços da Ortodontia desde que o Sr. se tornou ortodontista? Carlos Alexandre Câmara

Os principais avanços que assisti durante minha vida clínica foram:

(a) a colagem de acessórios diretamente sobre a superfície de esmalte, logo após o domínio da produção de anéis pré-fabricados para todos os dentes com acessórios soldados ou na forma de tak welded. O aparecimento de variações da técnica Edgewise (Straight-wire, Roth e outros), que fizeram com que a Ortodontia se tornasse mais conhecida e popular, pela simplicidade que trazem em si. Alguns referem-se ao aparelho como "inteligente", mas na prática é uma técnica totalmente voltada 
para o atendimento em massa, principalmente nos USA onde predominam os passos de alinhamento, nivelamento e fechamento de espaços em massa, sem medo da perda de ancoragem. O que mais se ouve nas clínicas como orientação para as auxiliares é: change the chain, que exemplifica bem as condições de mecânica simplificada predominante. Muitos são os profissionais que concordam com a afirmação que Edgewise deixou de ser uma técnica, passando a ser uma filosofia após as derivações criadas e difundidas. Aqueles que são instruídos e adotam a filosofia Edgewise têm o domínio de todas as derivações. Por outro lado, apesar de tentar muito, para mim foi impossível remover da Ortodontia o nome do "Dr. Edgewise". Ele, "Dr.", nunca existiu, sendo em verdade um termo do idioma Inglês, mas tem sempre alguém chamando-o de "PROFESSOR". Outra grande ajuda foi o advento dos elastômeros com suas diversas formas e utilidades, sendo conhecidos como Alastik, pois foram introduzidos por dois irmãos ortodontistas, que colocaram as iniciais de seus nomes no início e no final do termo "elastic", ficando Alastik, constituindo-se num dos maiores passos para simplificar o nosso trabalho. Acredito que, atualmente, existam bons ortodontistas que nunca utilizaram o coil spring e não sabem como empregá-lo, assim como não fazem a separação com fio metálico.

(b) as ligas de fio de altíssima flexibilidade, como por exemplo a de níquel-titânio (NiTi), embora eu utilize somente o redondo 0,014 ", mesmo assim aquecendo-o com uma chama bem fina na região da linha média, até o rubro, para que o fio perca a têmpera naquela região e evite maiores expansões do arco e, se necessário, na mesial e/ou distal dos caninos, em ambos os arcos.

(c) os avanços da cirurgia ortognática e os da distração osteogênica.

(d) o uso do computador em geral e, mais recentemente, suas maravilhas na obtenção de imagens tridimensionais por tomografia, dando maior impulso ao desenvolvimento dos diagnósticos e da cefalometria;

(e) a ancoragem esquelética, seja na forma de parafusos, placas ou de implantes osseointegrados, com finalidade ortodôntica ou protética. Penso que, em futuro próximo, os miniimplantes serão colocados pelo ortodontista de forma simples e segura, usando simplesmente um porta implantes, tendo em sua ponta os recursos para a anestesia local e o implante. Está aí uma idéia para pesquisas e para as indústrias.

(f) o substancial progresso do ensino e da pesquisa no Brasil, pois atualmente temos bons programas de especialização, mestrado e doutorado e, analisando os dados acima, podemos perceber e afirmar que o profissinal que não se atualizar ficará com grande dificuldade de exercer, eficientemente, a especialidade. Com base na ancoragem esquelética, está surgindo uma nova Ortodontia, que nos próximos dez anos estará totalmente voltada para estes recursos técnicos, sendo importante que o ortodontista tenha domínio tanto dos recursos clássicos como dos que estão surgindo. Este é um dos importantes aspectos da nossa profissão, a necessidade de constante atualização.

4) O Sr. teve a oportunidade de conviver com a época áurea do ensino da Ortodontia, onde, mesmo com as dificuldades existentes em relação à aquisição de material importado para o exercício da especialidade, se praticava o magistério por ideal e amor. Hoje, resguardando nobres exceções, observamos a prática mercantilista do ensino, onde a educação se tornou mais um meio de vida do que um ideal. E nesse contexto estão vários cursos de pósgraduação em Ortodontia que, mesmo sem a qualificação adequada, proliferam por todo o país. Que análise o senhor faz desse quadro? Fernando Habib

Sou de opinião que existe oportunidade para todos e que tudo tem sua evolução. "A época áurea do ensino da Ortodontia", como o Sr. diz, ainda existe e não é constituída de raras exceções. Veja o editorial Where have all the teachers gone?, escrito pelo Prof. Dr. David L. Turpin no American Journal de março do corrente ano. Todo profissional que é expoente em sua especialidade e permanece ou ingressa no magistério o faz por dile- 
tantismo, mas no íntimo eu acredito que seja para retribuir tudo que recebeu e o diferenciou. Citese o exemplo do Prof. Martins, que, mesmo sendo professor catedrático da Universidade do Brasil, submeteu-se a ser estudante novamente, tendo que aprender o idioma do país onde freqüentou curso para graduados e depois de formado iniciou o ensino da Ortodontia no Brasil, e com esta atitude conseguiu que outros fizessem o mesmo. Existem muitos professores em regime de tempo integral, muitos outros em tempo parcial, mas é vultoso o número de professores que se dedicam em "tempo de época áurea", isto é, praticam o magistério por ideal e amor, e isto sempre existirá, e o senhor, Dr. Habib, é um dos exemplos deste tipo de professor. Há no meio universitário aqueles que iniciam carreira por precisarem de emprego e continuam empregados do ensino a vida toda e jamais sentirão o verdadeiro sentido de ser professor, pois sempre serão apenas empregados do ensino. São estes, em sua maioria, que criam e dirigem os cursos mercantilistas, não tendo amor e respeito por aquilo que fazem, sendo movidos pela pecúnia. Dr. Habib, o que o fez pensar em uma "época áurea" foi o aparecimento dos cursos mercantilistas, os quais, infelizmente, são aceitos por um grande número de profissionais que desejam apenas o título ou a licença para praticar a especialidade. Acredito que os cursos deficientes ganham a fama de inadequados e fecham as portas, por falta de procura, e seus proprietários abrem um novo curso, nos mesmos moldes, em outro lugar que seja explorável. Eles pulam de galho em galho. O produto destes cursos são os profissionais insatisfeitos que acabam, em sua maioria, servindo de mão-deobra barata para as chamadas clínicas populares ou abandonam a especialidade. Os mais criteriosos procuram se qualificar em cursos melhores. A maioria dos profissionais de boa formação não analisa adequadamente estes aspectos e, geralmente, pensa que o profissional mal formado conseguirá sobreviver. Eu acredito que não sobreviva. Acredito, ainda, que, na oportunidade adequada, os profissionais de boa formação se unirão e farão a definitiva organização na Ortodontia brasileira. $\mathrm{Na}$ minha opinião falta pouco para que isso aconteça, alguns importantes passos já estão sendo dados.

\section{5) O senhor prefere tratar a má oclusão Classe II em uma ou duas fases? E quais os motivos e características clínicas que o levam a escolher uma das opções? Carlos Alexandre Câmara}

Quando possível, trato as más oclusões em geral em duas fases, pois é sempre vantajoso para os pacientes. Para isso, é importante que se inicie o tratamento da Classe II com forças aplicadas por aparelhos externos, sendo o do tipo Thurow o meu preferido - quando indicado, pois pode ser empregado em qualquer fase da evolução da oclusão (Fig. 1, 2). A Classe II é reduzida por predominância de movimento dentário, não sendo necessário aguardar as modificações esqueléticas por crescimento (Fig. 3). Até há bem pouco tempo, a grande maioria dos casos ortodônticos era tratada por aparelhos externos, com direção de forças específicas e recursos para movimento dentário controlados de tal maneira que, quando reduzido para Classe I, necessitava apenas de finalização (Fig. 6), conseguida por emprego de aparelhos do tipo Edgewise convencional, ou suas variações, tais como Straightwire, Roth e outros. As características dos casos a serem tratados em duas fases são: grandes overjets com exageradas projeções de incisivos, face longa por crescimento mandibular divergente, problemas verticais com linha de sorriso alta e mordidas abertas ou sobremordidas exageradas e todos os casos em que possam ser empregados os conhecimentos das extrações seriadas. Em todos estes casos você pode, e deve, fazer o tratamento em duas fases, pois o crescimento restante fará todas as compensações que forem necessárias, para o pleno equilíbrio funcional. Seja com ancoragem absoluta ou com aparelho extrabucal, o sucesso do tratamento dependerá da atualização do profissional, do consentimento do paciente e de seus responsáveis e de cooperação. A ancoragem absoluta pode ser um recurso no caso de paciente não cooperador. Os grandes overjets e as projeções exageradas de incisivos superiores devem ser corrigidos e aqueles dentes protegidos 
contra acidentes, o mais cedo possível. Quantos casos de fraturas e avulsões traumáticas dos anteriores superiores ocorrem, enquanto o paciente está à espera de um tratamento compreensivo, porque o profissional não gosta ou não sabe tratar em duas fases? Um detalhe que me preocupa nos casos de correções pelo emprego de aparelho fixo na dentadura mista é a inclinação distal dos incisivos laterais permanentes superiores - fase do patinho feio - que, se verticalizados precocemente, podem ter suas raízes movimentadas de encontro às coroas dos caninos permanentes, podendo resultar em sérios problemas. Nos casos que trato precocemente, com aparelhos fixos, faço a colagem dos braquetes dos laterais com as angulações invertidas, ou seja, de tal forma a manterem as inclinações dos laterais divergentes, e corrijo-as após os caninos permanentes terem irrompido. Quando o caso é tratado com o aparelho de Thurow esta preocupação não existe. Quando o aparelho de Thurow não está indicado, trato com aparelho fixo (4x2) Edgewise, isto é, na ausência de problemas verticais, principalmente os casos em que posso empregar os conhecimentos de extrações seriadas. Por exemplo, sei que estou tratando um caso de Classe II, mas estou aplicando em cada arco, separadamente, os conhecimentos de extrações seriadas. Assim, com a progressão do tratamento, quando estiver reduzida a Classe II para Classe I, terei resultados esqueléticos e dentários adequados para iniciar a segunda fase, sendo importante lembrar que, atualmente, devemos levar em consideração a ancoragem absoluta, que dispensa o uso de aparelhos extrabucais. Difícil responder plenamente esta pergunta, pois envolve conhecimentos amplos de crescimento, evolução da oclusão, extrações seriadas, mecânica e ancoragem absoluta, por isso fica-se com a impressão que a resposta está incompleta.

\section{6) O Sr. sempre foi perito em conseguir cooperação por parte de seus pacientes no uso de aparelhos extrabucais. Qual o segredo de seu sucesso neste item? Marco Antonio de Oliveira Almeida}

Não há segredo. A conduta é estar atento às
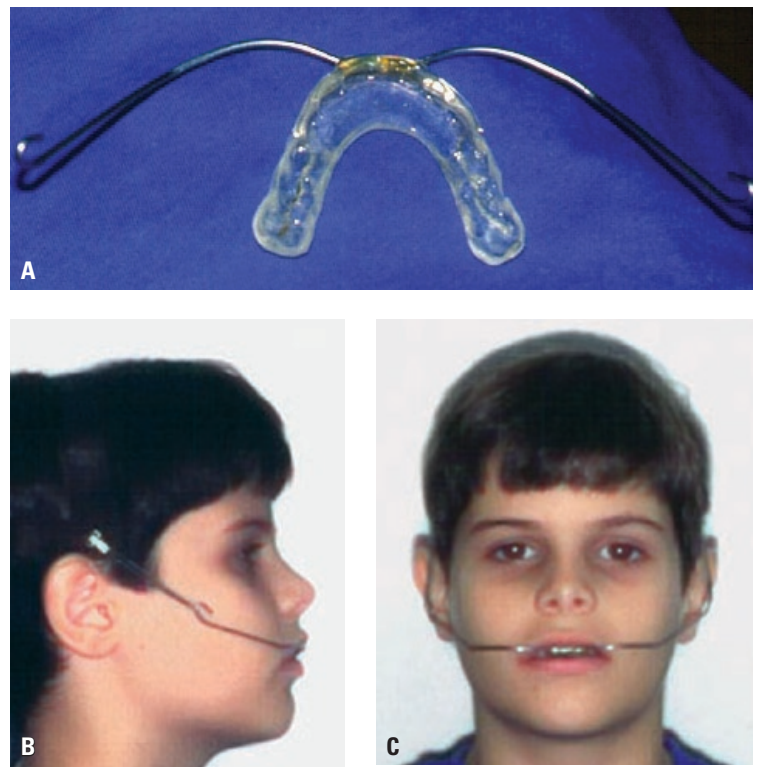

FIGURA 1 - A) Aparelho de Thurow convencional, confeccionado com um arco extrabucal, tendo o arco interno adaptado à superfície oclusal de dentes posteriores, decíduos ou permanentes, e envolto em resina acrílica, formando um splint, com a indispensável curva de Wilson. B, C) Aparelho de Thurow instalado no paciente.
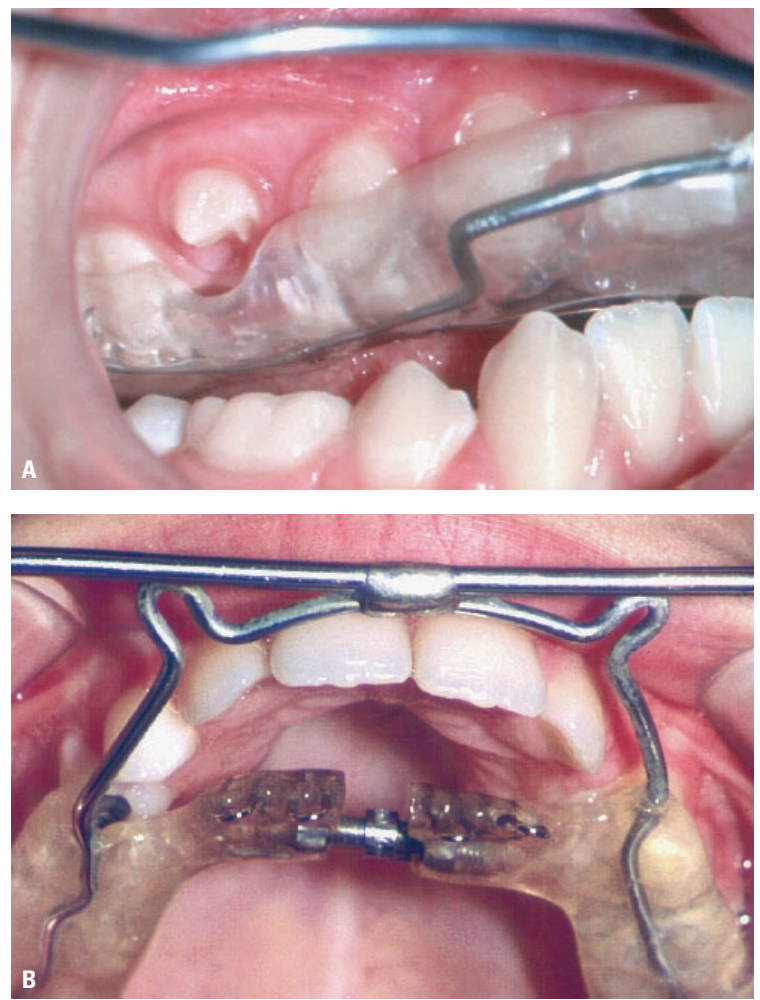

FIGURA 2 - Exemplos de versatilidade do aparelho de Thurow. A) Desgastes da porção acrílica, para permitir a erupção dos dentes permanentes e B) remoção do acrílico nos incisivos, para permitir o fechamento da mordida aberta anterior, e utilização de parafusos expansores, para correção de mordidas cruzadas, assim como grades para corrigir a postura da língua. 
modificações apresentadas a cada consulta e conversar com o paciente sobre o compromisso assumido, verificando, com o mesmo, os sinais de uso do aparelho. Por exemplo: no caso de aparelho tipo Klöehn, se os molares de ancoragem apresentam mobilidade e, no caso de aparelho tipo Thurow, se houve diminuição do overjet, que é em média de $1 \mathrm{~mm}$ por mês. Na maioria dos casos solicito que os responsáveis não façam o controle do uso dos aparelhos externos. Combino com o paciente, se ele concordar, que a mamãe ou o papai poderão lembrá-lo, a maioria recusa os lembretes e cuida do aparelho e de seu uso com eficiência, certamente para provar que é capaz. Tudo isso com muita conversa e muita paciência. Imposição não funciona. Tenho por conduta, nos casos de aparelho extrabucal sendo usado junto com aparelho fixo completo, e evidenciado o não uso, dizer ao paciente que naquela dada consulta nada tenho a fazer, pois o tratamento depende do uso do extrabucal. Assim sendo, dispenso o paciente sem nada fazer, o que fica incômodo e recomendo que a cooperação seja melhorada. $\mathrm{O}$ paciente volta para casa sem ser verdadeiramente atendido. Se você trocar elásticos ou amarras o paciente julgará que algo foi feito em benefício do tratamento e continuará sendo mau cooperador. Tenha coragem, honestidade e amor. Com o advento da ancoragem esquelética, os ortodontistas terão mais recursos para estes tratamentos, mas é importante dominar todas as técnicas, visto que o paciente ou seu responsável poderá não aceitar os procedimentos cirúrgicos necessários na ancoragem esquelética. Uma conduta que muito tem ajudado é a que denominei intermitente, ou seja, nos casos difíceis de terminar por falta de cooperação, solicito ao paciente que use o extrabucal o maior tempo possível. Diante da falta de colaboração do paciente, recomendo o uso de elásticos intrabucais, após a estabilização do arco inferior com fio retangular de espessura máxima, com finalidade de ancoragem.

7) Acredito que o Sr. seja um dos ortodontistas que mais utilizou o aparelho de Thurow para correção de problemas verticais. Sendo assim, depois da grande experiência acumulada, quais seriam as suas considerações acerca deste aparelho? Fernando Habib

$\mathrm{Eu}$ o chamo de aparelho super-eficiente. Por que? Porque além de dar bom controle vertical, ântero-posterior e transverso (Fig. 1, 2), é um aparelho muito versátil, sendo fácil de o paciente se adaptar, assim como o ortodontista modificá-lo de acordo com as necessidades que possam surgir (Fig. 2A). É de fácil construção e econômico, podendo ser utilizado precocemente; também é protetor dos incisivos contra fraturas e avulsões por acidentes (lembrem-se dos grandes overjets e projeções de incisivos superiores). Na grande maioria das vezes leva o paciente a convencer-se de que não tendo qualquer outro aparelho sobre os dentes fica claro que não existe outra alternativa, a não ser o uso do que ele possui. Considero ainda que o maior efeito a se esperar resulta mais de movimento dentário, pois os resultados são obtidos em curto espaço de tempo e não seriam suficientes para modificações ortopédicas (Fig. 3). É possível conseguir-se maior modificação ortopédica, mas o tempo ou duração do tratamento deverão ser prolongados e as forças empregadas deverão ser abrandadas. Uma das modificações importantes é o controle da linha de sorriso, que se obtém pelo emprego deste aparelho (Fig. 4), que pode ser em qualquer fase da evolução da oclusão, e quanto mais cedo melhores os resultados.

\section{8) Existe alguma restrição para 0 uso do aparelho de Thurow no tratamento da Classe II esquelética em pacientes com crescimento? Carlos Alexandre Câmara}

Existe. Nos pacientes portadores de crescimento mandibular convergente (casos de Classe II, divisão 2), ou seja, os casos de síndrome da face curta, uma vez que o aparelho de Thurow não permite anular a resultante vertical intrusiva, o que agravaria estes casos.

9) A recidiva no tratamento da mordida aberta é fato notório. Como o Sr. aborda este 

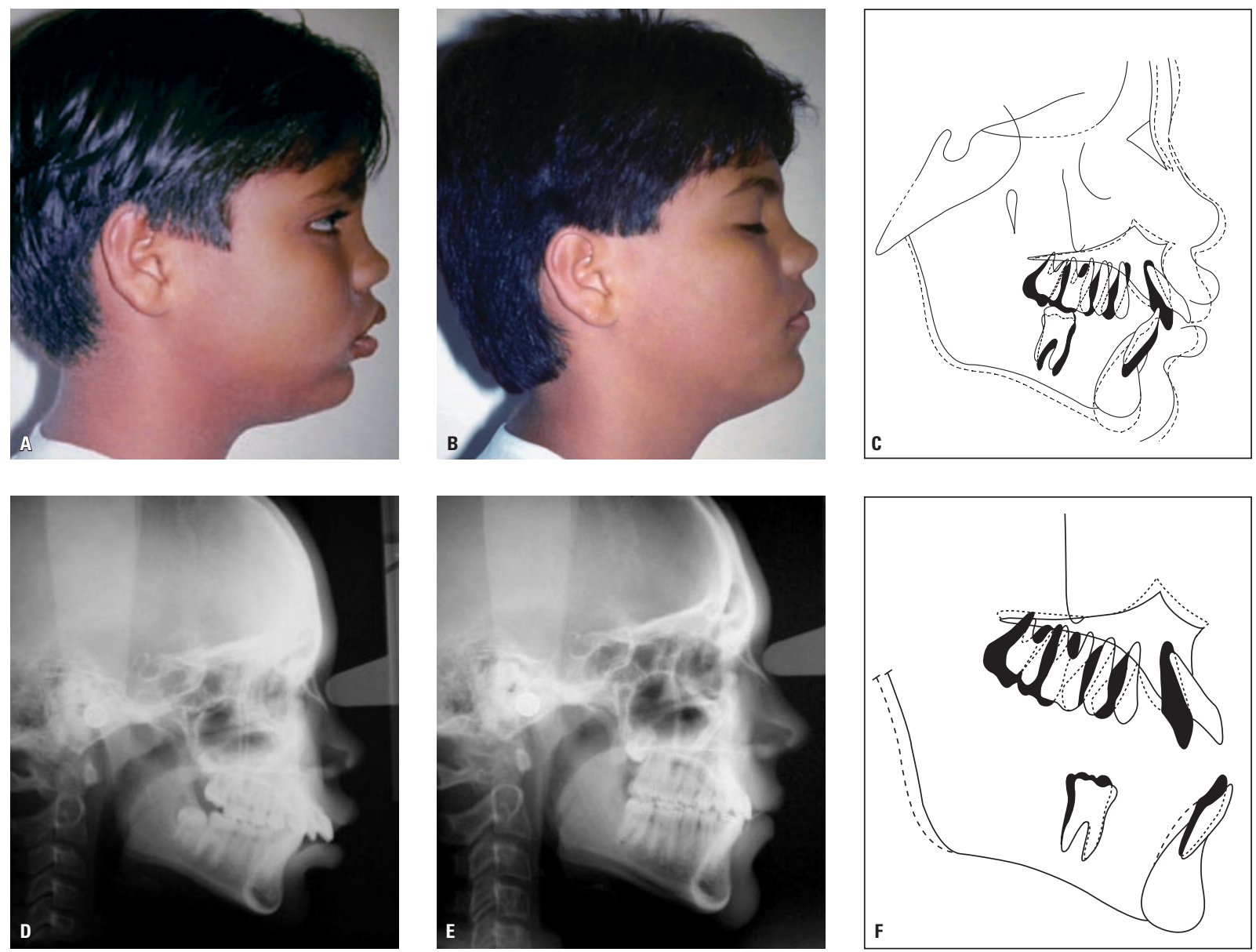

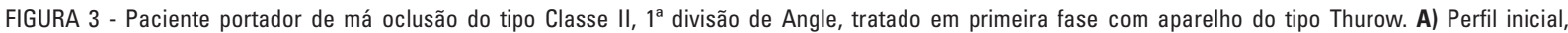
B) perfil após um ano de tratamento, D) radiografia cefalométrica de perfil inicial, E) radiografia cefalométrica de perfil após um ano do uso do aparelho de Thurow, C) sobreposição total, F) sobreposição parcial da maxila e sobreposição parcial da mandíbula. Observe a predominância de movimento dentário em sentido distal, crescimento quase nulo, assim como a ausência de extrusão dos dentes posteriores, resultado do uso do aparelho de Thurow.
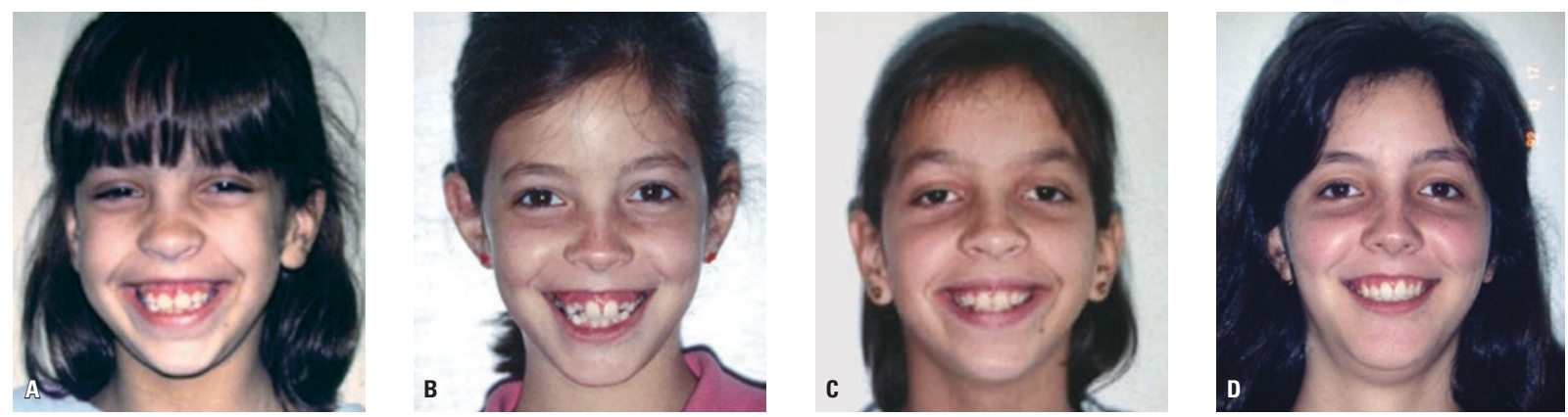

FIGURA 4 - A, C) Paciente sorrindo antes do tratamento com aparelho de Thurow e B, D) paciente sorrindo após o tratamento ( $1^{\text {a }}$ fase). Houve melhora na exposição de gengiva durante o sorriso, pelo controle vertical do aparelho de Thurow. 
fato com seus pacientes e responsáveis? Marco Antonio de Oliveira Almeida

A recidiva da mordida aberta anterior não deveria ocorrer, pois o ortodontista tem meios terapêuticos de tratá-la, com eficiência, removendo a causa, quer por meio de aparelhos ortodônticos ou recurso cirúrgico, estes mais raros, sendo fundamentais o diagnóstico e plano de tratamento corretos. Atualmente, tenho a convicção de que se a mordida aberta recidivou é porque eu falhei no diagnóstico e, conseqüentemente, no tratamento. O mais efetivo aparelho para correção da mordida aberta anterior é o que eu chamo de agressivo, que utiliza as pontas ativas ou esporões, e minha orientação é que o mais importante no emprego destas é iniciar o tratamento com pequenas pontas (de 1 ou $2 \mathrm{~mm}$ ) e aumentá-las com o tempo, em número e tamanho (Fig. 5). Estes aumentos são necessários para orientar ou forçar a língua para sua posição normal (Fig. 5). Os casos cirúrgicos são raros e estão mais indicados nas macroglossias e freios linguais. Mesmo utilizando-se estas formas agressivas de tratamento, alerto ao paciente que podem existir dificuldades, sendo possível a recidiva, o que demandará mais tempo com o uso de pontas ativas. Este assunto por si só, gera um curso de 8 horas, possivelmente.

10) Como o Sr. conduz os seus casos ortodônticos, após finalização, reconhecendo - paciente como membro permanente da nossa clínica privada? Até quando este acompanhamento deve existir e quais são os procedimentos realizados neste período, que compreende a contenção e pós-contenção do tratamento ortodôntico? Fernando Habib

Sempre procuro incentivar o paciente para que volte, conforme marcado, para controle da contenção, mas não é por esta razão que podemos considerá-lo "membro permanente da clínica". Os meus procedimentos para a contenção, na maioria das vezes, são os mais simples, consistindo em uma barra fixa (permanente, se possível) de canino a canino no arco inferior, que construo de forma direta, com fio 0,028 ", com uma curva uniforme que acompanhe a superfície das faces linguais de canino a canino, sem reentrâncias ou ressaltos, a não ser que exista alguma anomalia de forma dos dentes anteriores inferiores. Uma placa tipo Hawley na maxila, que pode ser do tipo wrap-around, se necessário. Após remover o aparelho fixo e instalar os aparelhos de contenção, nova consulta é marcada para após um mês, dando tempo para que o paciente se habitue aos novos aparelhos ou, se for o caso, para ouvir atentamente suas queixas e solucioná-las. Nesta consulta examino toda a documentação, inicial e final, e oriento novamente o paciente sobre os sistemas de contenção e como utilizá-los, como descrito a seguir: no primeiro ano a recomendação é de uso em tempo integral - dia e noite - podendo, uma vez por semana, suspender o uso por um determinado período de tempo (não mais que seis horas, para ir a uma festa, por exemplo), deixando o aparelho, limpo, dentro d'água. No segundo ano a placa será utilizada durante a noite, colocando-a após o jantar e removendo pela manhã, mantendo sempre bem limpa dentro d'água, quando não em uso. No terceiro e quarto anos, usar somente para dormir. A partir do quinto ano usar às segundas, quartas e sextasfeiras, somente para dormir. Os pacientes aceitam estas modalidades com facilidade e há mais quatro aspectos que discuto freqüentemente com eles: a) higiene, b) necessidade do uso regular da contenção, c) a procura urgente de atenção especializada no evento de perda ou deformações dos aparelhos e d) o controle de cáries, por radiografia interproximal. Para aqueles que necessitam, controlo os terceiros molares. É adequado marcar seu paciente periodicamente e é minha rotina marcar revisões a cada três meses no primeiro ano de contenção e a cada seis meses no ano seguinte. Após esse período deixo a critério do paciente, com uma consulta por ano ou quando ele necessitar, sendo enfatizado o valor ou importância de uma radiografia interproximal por ano.

Aproveito para lembrar aos colegas certos recursos que não vejo com a devida freqüência e que considero de grande importância: no decorrer do segundo ou terceiro ano de contenção, principalmente nos casos sem extrações, aliviar o acríli- 

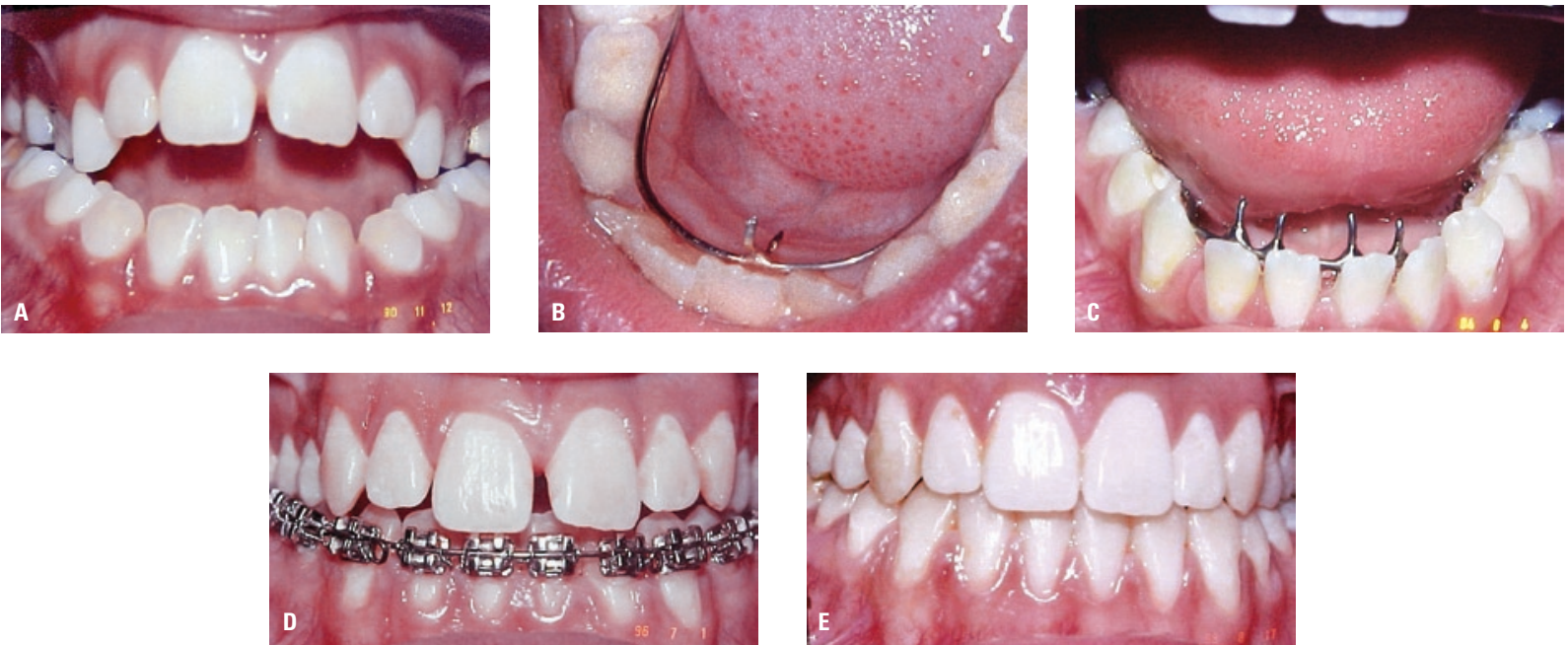

FIGURA 5 - A) Mordida aberta anterior, B) pontas ativas para 0 início do tratamento, C) pontas ativas aumentadas em número e tamanho, forçando a língua para a posição normal, D) aspecto da oclusão sem que nada tenha sido feito no arco superior, que foi conformado pela posição normal da língua $e$ E) caso tratado após remoção das pontas ativas e um período de observação da possibilidade de recidiva da mordida aberta.
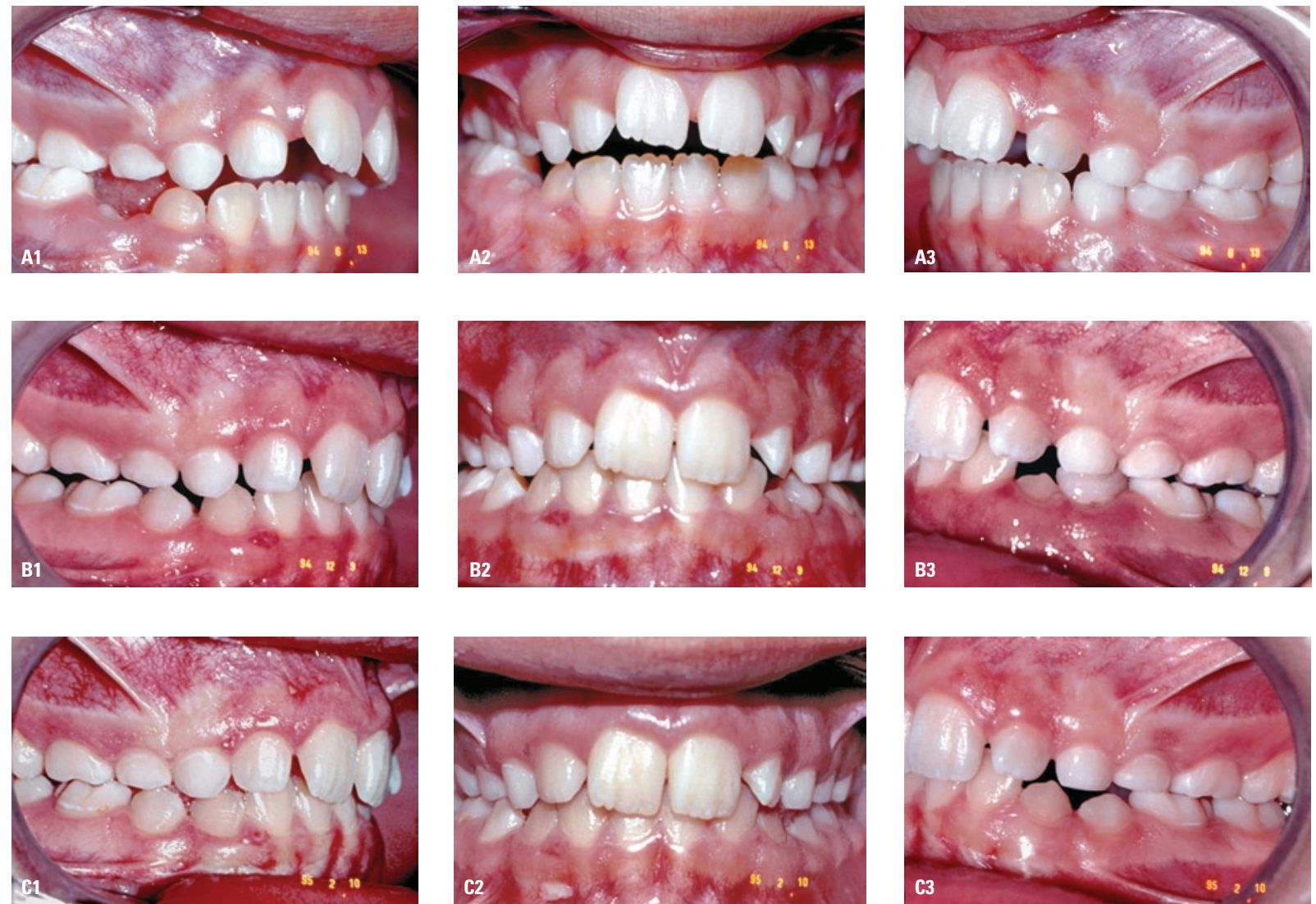

FIGURA 6 - Exemplo de caso tratado em duas fases com aparelho de Thurow, onde houve controle ântero-posterior, vertical e transverso. A) Fotografias intrabucais iniciais apresentando grande overjet, mordida cruzada posterior e mordida aberta anterior. B) Fotografias intrabucais seis meses após o início do tratamento, apresentando a mordida aberta corrigida, melhora da mordida cruzada posterior e do overjet. C) Fotografias intrabucais oito meses após o início do tratamento, houve a correção de todas as deficiências descritas inicialmente, tornando a segunda fase do tratamento mais simples, reduzindo o tempo de tratamento com aparelhos fixos. 
co, fazendo um recorte na área dos pré-molares e afastando o grampo nas placas wrap-around, para dar liberdade aos pré-molares e se conseguir, por acomodação, a melhor intercuspidação. Recomenda-se que toda placa deva ser construída com um batente anterior passivo, pois não há como prever o comportamento da sobremordida e, além disso, é necessário que o grampo de Hawley fique acima do limite do acrílico, pois se o grampo ficar abaixo daquele limite pode ocorrer movimento de coroa para palatina e da raiz para vestibular, conforme ensinava o Prof. Martins. Também aprendi com o Prof. James Jensen que toda contenção deve ser proposta ao paciente como permanente. Esclareço a todos eles que não há uma forma de detectar se haverá tendência a algum tipo de recidiva; e sendo o apinhamento uma característica do envelhecimento do ser humano e que acontece na grande maioria das pessoas, é válido propor ao paciente que as contenções sejam em caráter permanente, ou deixando a critério do mesmo a ocasião para interromper o uso, sendo avisado do possível aparecimento de recidivas. É o que faço, e por isso dificilmente tenho paciente em pós-contenção.

Para melhorar as condições das contenções, utilizo um final de tratamento um pouco diferente. A seguinte seqüência de remoção dos aparelhos fixos tem dado bons resultados: quando dou por finalizado o tratamento, instalo no arco inferior a barra de canino a canino, confeccionada de forma direta e, após sua colagem, removo apenas o arco ortodôntico e deixo a oclusão se ajustar mais, pela função. Isto pode durar de dois a três meses e é muito importante ter o arco superior estabilizado. No segundo ou terceiro mês removo a parte posterior do aparelho inferior, deixando os braquetes de canino a canino. $\mathrm{Na}$ consulta seguinte removo todo o aparelho superior e faço a moldagem para a placa de contenção, sendo de máxima importância anotar naquela consulta a altura do batente, para que fique passivo e se defina se a placa será Hawley ou wrap-around, avaliando-se os espaços entre dentes ocluídos, se permitem a passagem do fio do grampo de Hawley. Nos casos de extração de primeiros pré-molares é mais freqüente ter-se estes espaços. O grampo de Hawley é melhor para conter que o wrap-around, sendo mais estável e deformando menos. Após a moldagem superior, marco consulta para instalar a placa de contenção, não permitindo que o espaço seja de mais de uma semana, e prometo ao paciente que removerei o restante do aparelho inferior naquela consulta e, ao mesmo tempo, faço a moldagem e as fotos. Não tenho tido evasão de pacientes após a remoção do aparelho, sem instalar a contenção. Se por acaso o paciente não retornar para a instalação da placa, ele fica com o restante do aparelho no arco inferior e terá interesse em voltar ao consultório, o mais rápido possível. Esta conduta tem dado tranqüilidade para a remoção do aparelho e não necessito de longas consultas para fazê-lo. Outro ponto interessante é o comportamento dos pacientes em relação à placa de contenção. No início de minha carreira, eu colocava a placa de contenção incluída no orçamento do tratamento, sendo desconhecido pelo paciente o valor da placa, e ocorriam muitas perdas. Aprendi que fazendo com que o paciente tome conhecimento do quanto custa uma placa de contenção, as perdas se reduziram quase a zero. Alerto ao paciente que existe um local onde a placa não quebra e não é perdida - dentro da boca. A contenção inferior, isto é, a barra de canino a canino, em alguns casos solta-se com certa freqüência, sendo que faço a recolagem por duas ou tres vezes, e se cair novamente soluciono o problema construindo uma nova barra de canino a canino, numa curva uniforme e bem adaptada fazendo suas extremidades mais longas, terminando $1 \mathrm{~mm}$ aquém da distal de cada canino. Com a roda de caborundum faço o arredondamento de suas pontas e colo somente nos laterais inferiores, com excelentes e duradouros resultados.

\section{1) Como o Sr. avalia o futuro da Ortodon- tia no Brasil? Carlos Alexandre Câmara}

A Ortodontia está ainda se organizando no Brasil e, para avaliar seu futuro, é necessário conhecer dados do passado e reconhecer que, pelo caminho já percorrido, existem grandes possibilidades desta liderar a organização de grande parte das especiali- 
dades da Odontologia nacional, pois após este tão difícil processo, sem dúvida, será o modelo para diversas outras. É a primeira especialidade odontológica reconhecida nos EUA. Aqui no Brasil foi a primeira a ser ministrada no ensino para graduados em uma Universidade, em tempo integral, e continua nos caminhos que o Prof. José Édimo Soares Martins vislumbrou e colocou de forma séria, tendo como principal objetivo o ensino formal, tornando-se exemplo para a formação de diversos outros centros de ensino, do norte ao sul de nosso país. A qualidade e capacidade dos profissionais formados nestes centros não deixam nada a dever aos centros estrangeiros. Não posso deixar de citar o relevante papel dos professores, chamados pioneiros, que com muito sacrifício foram ao exterior buscar meios e conhecimentos para o ensino aqui no Brasil. Estes são, de acordo com o que posso me lembrar: Prof. José Édimo Soares Martins (RJ), Prof. Carlos de Souza Telles (RJ), Prof. Antonio Carlos Peixoto da Silva (RJ), Prof. S. Interlandi (SP) e Prof. Décio Martins (SP), que foram em busca de ciência ortodôntica para transmitir aos brasileiros. É adequado lembrar que o Prof. Dr. José E. S. Martins, por ser contrário a ter seu nome em causas políticas da Ortodontia, discretamente fez a aproximação dos profissionais expoentes na época (1954/1955), os quais lideravam pequenos grupos, e articulou, sem ferir vaidades, a fundação da Sociedade Brasileira de Ortodontia, que tem sido, nos últimos cinqüenta anos, um importante órgão de classe, que serviu de modelo para a fundação de diversos outros, em diferentes estados. Outro fator que contribuiu e ainda contribui para o sucesso da Ortodontia no Brasil é o convite que se faz a ortodontistas expoentes, do mundo todo, inclusive do nosso país, para ministrar palestras e cursos organizados pelas sociedades de Ortodontia. São muito válidos para atualizar o profissional brasileiro. Com base nestes dados, posso afirmar que a massa de profissionais de boa origem, que está sendo formada em nosso país, será coesa, trabalhará e resultará no merecido e grandioso futuro da Ortodontia brasileira. Considere pelo Sr. mesmo, que é um profissional de altíssima qualificação, sendo produto do ensino inteiramente nacional e, com certeza, está construindo o futuro da nossa especialidade. Sinta-se orgulhoso disto e considere que há muitos outros, competentes, e que, sem perceber, estão dando o melhor de si, para o sólido futuro da Ortodontia nacional.

\section{Carlos Alexandre Câmara}

- Especialista em Ortodontia FO-UERJ.

- Consultor Científico da Revista Dental Press de Estética.

- Diplomado pelo Board Brasileiro de Ortodontia.

Fernando Antônio Lima Habib

- Ortodontista pela UFRJ.

- Professor de Ortodontia da UFBA.

\section{Marco Antonio de Oliveira Almeida}

- Mestre em Ortodontia pela UFRJ e Livre Docente pela UERJ.

- Professor Titular de Ortodontia da UERJ.

- Visiting Professor do Departamento de Ortodontia da Universidade de Carolina do Norte.

\section{REFERÊNCIAS}

1. ARAÚJO, T. M.; NASCIMENTO, M. H. A.; BEZERRA, F.; SOBRAL, M. C. Ancoragem esquelética em Ortodontia com miniimplantes. Rev. Dental Press Ortodon. Ortop. Facial, Maringá, v. 11, p. 126-154, jul./ago. 2006.

2. JUSTUS, R. Treatment of anterior openbite: a cephalometric and clinical study. Assoc. Dent. Mexico, Mexico, D.F., v. 33, p. 17-40, 1976.

3. LOPES-GAVITO, G.; WALLEN, T. R.; LITTLE, R. M.; JOONDEPH, D. R. Anterior open-bite malocclusion: a longitudinal 10-year postretention evaluation of orthodontically treated patients. Am. J. Orthod., St. Louis, v. 87, no. 3, p. 175-186, Mar. 1985.

4. PROFFIT, W. R.; MASON, R. M. Myofunctional therapy for tongue-thrusting: background and recommendations. J. Am. Dent. Assoc., Chicago, v. 90, no. 2, p. 403-411, Feb. 1975.

5. THUROW, R. C. Craniomaxillary orthodontic correction with en masse dental control. Am. J. Orthod., St. Louis, v. 68, no. 6, p. 601-624, Dec. 1975

6. TURPIN, D. L. Where have all the teachers gone? Am. J. Orthod. Dentofacial Orthop., St. Louis, v. 131, no. 3, p. 297, Mar. 2007. 